\title{
Social-emotional problems observed in gifted children
}

\author{
Adile Gülşah SARANLI*
}

Nilgün METIN***

\begin{abstract}
The goal of this paper is to increase awareness related to social-emotional problems experienced by gifted children lacking support systems suited to their needs and to describe solutions to minimize associated risks. The concept of "gifted" is defined and reasons for differences in social-emotional needs of gifted children together with how asynchronous development can be an important factor effecting their social-emotional states are explained. Different problems in this context are then considered, including loneliness, perfectionism, stress, depression and suicide. Finally, discussion and suggestions on social-emotional situations that need further research to ensure that gifted children can become emotionally healthy adults are presented.
\end{abstract}

Keywords: Gifted children, Social-emotional problems.

\footnotetext{
${ }^{*}$ Counseling Psychologist and Child Development Specialist (Ph. D.)

E-mail: gsaranli@gmail.com

* Prof. Dr., Hacettepe University Faculty of Health Sciences, Dept. of Child Development, Ankara, Turkey. E-mail: enmetin@gmail.com
} 


\section{SUMMARY}

Purpose and significance: The main purpose of this paper is raising consciousness about social-emotional problems of gifted children by identifying and clarifying common misconceptions related to these problems. Existing studies emphasize a number of different aspects of social-emotional problems experienced by gifted children, with results seemingly affected by their degree of giftedness. This naturally leads to the conclusion that when the gap between the gifted child and his/her typically developing peers, is very large and common interests are sparse, additional measures must be taken in order to protect the psychological well-being of the gifted child.

Resources: Contemporary research reveals that gifted children can be healthy, attractive and active individuals with strong personalities and social skills. Nevertheless, constant expectation of success from gifted children without regard to the nature of their social and emotional well being may impede their progress in developing a healthy self-awareness, a balanced circle of friends and a comfortable school environment (D'souza, 1994; Preuss and Dubow, 2004; Robinson, Shore and Enersen, 2007; Swanepoel, 1987). Another important observation is that the degree of giftedness as an important factor that affect the occurrence of social-emotional problems.

Results: The family, the personality and the intelligence level of gifted child are all important supporting components in their social-emotional health. In many cases, gifted children may even be more compatible and develop healthier character structures than their peers when they are provided with appropriate home and school environments.

Conclusion: Despite the fact that there has been significant research on social-emotional problems of gifted children in the international literature, researchers in Turkey have just recently shown interest in this topic. Even though there are studies which specifically focus on social-emotional problems, there is a clear need for studies on other aspects of the problem including different age groups and types of giftedness. Considering that giftedness can manifest itself in different, culture-dependent forms, different social-emotional problems and associated solutions in Turkey need to be studied further while also taking cultural differences into account. In conclusion, one of the longer term goals in this context should be to provide the necessary environment for gifted children, who have always been an important driving force for any society, to develop psychologically healthy personalities and achieve happiness. 


\section{Üstün Yetenekli Çocuklarda Gözlenen Sosyal-Duygusal Sorunlar}

\section{Adile Gülşah SARANLI*}

\author{
Nilgün METÍN**
}

ÖZ. Bu çalışmanın amacı, üstün yetenekli çocukların uygun ortam ve ihtiyaçlarına yönelik destek sistemleri sağlanamadığında yaşayabilecekleri sosyal-duygusal sorunları ve bunlarla ilgili yanlış inanışları ortaya koyarak, bu sorunların önüne geçilmesi için ailelerin ve eğitimcilerin farkındalığının artırılmasıdır. Bu amaçla, öncelikle üstün yetenekli kavramı tanımlanmış ve üstün yetenekli çocukların sosyal-duygusal ihtiyaçlarındaki farklılığın sebepleri açıklanmıştır. Üstün yetenekli çocukların yaşadıkları sosyal-duygusal sorunların önemli kaynaklarından biri olarak görülen eş zamanlı olmayan gelişim konusuna değinilmiştir. Üstün yetenekli çocuklarda görülebilen sosyal-duygusal sorunlardan olan sosyal izolasyon (dışlanma/yalnızlık), mükemmeliyetçilik, stres, depresyon ve intihar konuları, sebepleriyle ve ilgili araştırma sonuçlarıyla birlikte ele alınarak açıklanmıştır. Ayrıca üstün yetenekli çocuklarda gözlenebilen bu sorunların önlenebilmesi için bazı çözüm önerilerinde bulunulmuştur.

Anahtar Sözcükler: Üstün yetenekli çocuklar, Sosyal-duygusal sorunlar.

\footnotetext{
* Psikolojik Danışman ve Çocuk Gelişimi Uzmanı (Dr.) E-posta: gsaranli@gmail.com

Prof. Dr. Hacettepe Üniversitesi, Sağlık Bilimleri Fakültesi, Çocuk Gelişimi Bölümü, Ankara, Türkiye. E-posta: enmetin@gmail.com
} 


\section{GİRIŞ}

Sosyal-duygusal ihtiyaçlar, bireyin yaşadığı ortama sağlıklı uyum sağlayabilmesi için gerekli tüm durumları kapsar. Bu ihtiyaçlar, bireyin kendi içindeki ve kişiler arasındaki iyi olma durumunu ve başarısını tanımlamakla birlikte, kişinin kendini ve diğerlerini anlamasını ve duygularını düzenleyerek rahatça ifade edebilmesini içerir (Neihart, 2006; Şenol, 2006). Tüm çocukların zaman zaman sosyal-duygusal sorunlar yaşayabileceği bilinmekle birlikte, üstün yetenekli çocukların ihtiyaçlarının bazı açılardan farklılaştığı ve bu sebeple de zaman zaman özel destek sistemlerine ihtiyaç duyabilecekleri gözden kaçırılmamalıdır (Delisle ve Lewis, 2003; Freeman, 1985).

Üstün yetenekli teriminin anlamı ilk kullanılmaya başlandığ zamanlardan günümüze değin pek çok değişiklik göstermiştir. Başlangıçta bu kavram yetişkinler tarafindan olağanüstü derecede başarılı çocuklar için kullanılırken, daha sonra çocukların bazı testlerden geçirilmesi sonucu dağılımın en üstte kalan \% 2'lik kısmı için uygun görülen bir tanım haline gelmiştir (Freeman, 1985). Günümüzde ise üstün yeteneği tanımlamada daha farklı ölçütler kullanılmaktadır. Örneğin, Morelock (1992) üstün yeteneği "normal olarak kabul ettiğimiz standartlardan hem nitelik hem de nicelik olarak farklı içsel deneyimler ortaya koyan ve ileri bilişsel becerileri içeren eş zamanlı olmayan gelişim” olarak tanımlamıştır. Son zamanlarda zekanın çoklu bileşenlerinin olduğuna ilişkin gerçekleştirilen güncel çalışmalar da oldukça dikkat çekmektedir (Gardner, 1993). Renzulli'nin "Üçlü Halka" modelinde ise ortalama üstü yetenek, yüksek düzeyde görev bilinci ve yüksek düzeyde yaratıcılık arasındaki etkileşimler üstün yeteneği tanımlamada temel olarak alınmaktadır (Reis ve Renzulli, 2004). Dabrowski'nin "aşırı duyarlılıklar kavramı” da üstün yetenekli çocukları daha iyi anlayıp tanıyabilmemizde bizlere 1şık tutan bir başka önemli tanımdır (Akt. Ackerman, 1997) Dabrowski'nin teorisi, deneyimlerin insanın duyarlılıklarının gelişimi üzerinde oynadığı önemli role değinir ve duyguların bu gelişim potansiyelindeki rolünü vurgular. Beş farklı formda aşırı duyarlılık alanı tanımlanmıştır. Bunlar; psikomotor, duyusal, hayali, entellektüel ve duygusal duyarlılık alanlarıdır. Dabrowski'ye göre, düşünce ve duygudaki duyarlılık ve zenginlik, hayalgücündeki canlılık ile ahlaki ve duygusal duyarlılık, üstün yetenekli bireylerin dünya ile daha gelişmiş iletişimler kurmalarına önayak olmaktadır

Konu edilen tanımlardan yararlanılarak bu çalışmada üstün yetenekli çocuk tanımı, kendi yaşındaki çocuklarla karşılaştırıldığında çeşitli yönlerden üstün özellikler gösteren çocuklar için kullanılmıştır. Bu çocuklar akranlarına göre tüm zihinsel beceriler ve öğrenme potansiyellerinde üstün 
olabilecekleri gibi, sadece belirli alanlarda fark edilir derecede üstünlük gösterebilirler. Bu çocuklar genellikle çok hızlı öğrenir, yaşıtlarının ötesinde geniş bir bilgi dağarcığına sahiptirler ve problem çözme, analiz-sentez yapma gibi üst zihinsel seviyelerde düşünürler. Meraklıdırlar, çok soru sorar ve derinlemesine araştırmayı severler. Bu tip çocuklarda genellikle erken dil gelişimi gözlemlenmektedir (Metin, 1999).

Tüm bu farklı ve üstün bilişsel özellikleri, üstün yetenekli çocukların sosyal ve duygusal olarak da farklı ihtiyaçlara sahip olabileceklerini düşündürmektedir. Bununla birlikte bilişsel olarak üstün olmalarına karşın, fiziksel ve duygusal gelişimlerinde yaşlarına uygun tipik özellikler gösterebilirler (Koshy, 2002). Bu kendilerinin ve çevrelerindekilerin kafasını karıştırarak oluşabilecek sorunları daha da karmaşık hale getiren bir durumdur. Üstün yetenekli çocukların gelişim alanlarının hızları arasında uyumsuzluk olmasından kaynaklanan farklı sosyal ve duygusal ihtiyaçları ile bunun sonucunda oluşabilecek sorunlar yıllardır üzerinde çalışılan bir konudur. Üstün yeteneklilerin eğitimi konusunda öncü olarak nitelendirilebilecek olan Hollingworth'un çalışmalarında bu çocukların özel ilgi gerektirebilecek sosyal-duygusal ihtiyaçları olduğu vurgulanmıştır (Akt. Neihart, 2006). Üstün yetenekli çocukların zihinsel olarak çok yeterli olmalarına karşın sosyal-duygusal ve fiziksel olarak yetersiz oldukları yönünde yaygın bir görüş bulunmaktadır. Ancak, bu görüş yapılan pek çok bilimsel araştırmada destek bulamamıştır (D'souza, 1994; Preuss ve Dubow, 2004; Swanepoel, 1987). Örneğin, geniş bir örneklemle gerçekleştirilen Terman'ın 1920'li yıllarda başladığı ve bazı konu başlıkları günümüzde de devam ettirilmekte olan boylamsal çalışmalarında da üstün yetenekli çocukların uyumsuz davranış, intihar eğilimi ve suç işleme gibi durumları toplum geneliyle karşılaştırıldığında daha az düzeyde gösterdikleri görülmüştür (Akt. McMann ve Oliver, 1988). Ancak, bir kişinin üstün yeteneklere sahip olması sebebiyle akranlarından farklı olarak yaşayabileceği sosyal deneyimler ve farklı duygularının olması da kaçınılmazdır. Bu sebeple üstün yetenekli çocukların akademik, benlik algısı, sosyal beceriler ve duygusal olarak sağlıklı olma gibi pek çok boyutta değerlendirilmesi gereklidir (Neihart, 2006).

Reis ve Renzulli'nin (2004) çalı̧̧malarında üstün yetenekli çocukların sağlıkl1, çekici, pek çok alanda aktif, güçlü kişiliklere ve sosyal yeterliliklere sahip bireyler olabildiklerini gösteren pek çok araştırma gözden geçirilmiştir. Bununla birlikte, yukarıda da belirtildiği üzere sosyal-duygusal gelişimlerindeki risk oluşturabilecek etmenler ele almadan, onlardan sürekli olarak başarı beklemek, sağlıklı bir benlik algısı ile dengeli bir okul ve arkadaşlık çevresi oluşturmalarını zorlaştıracaktır (Robinson, Shore ve Enersen, 2007). Bu amaca yönelik olarak Amerikan Ulusal Üstün Yetenekli 
Çocuklar Birliği'nin yaptığı bir araştırma, üstün yetenekli çocukların sosyalduygusal ihtiyaçlarındaki farklılığın anlaşılabilmesine yardımcı olmuştur. $\mathrm{Bu}$ çalışmada okul ortamında üstün yetenekli çocukların mutlu ve sağlıklı olabilmeleri için gerekenler incelendiğinde sosyal ve duygusal ihtiyaçlarını karşılayabilmek için en az üç farklı akademik koşul olduğu ortaya çıkarılmıştır. Bunlar: a) benzer ilgi ve yeteneklere sahip bireylerle aynı ortamda bulunma ve çalışma firsat1, b) içinde bulunduğu normal sınıf koşullarında uygun seviyede zorlanma ve c) esnek bir müfredatla çalışabilmedir (Akt. Neihart, 2006). Neihart'ın (1999) bir başka çalışmasında da üstün yeteneğin tipi ve derecesinin, uygun eğitimsel ortama sahip olmanın ve çocuğun kişisel özelliklerinin, üstün yetenekli çocukların psikolojik olarak sağlıklı olabilmelerini etkileyen önemli unsurlardan oldukları ortaya konulmuştur.

Üstün yetenekli çocukların sosyal-duygusal gelişimlerini inceleyen pek çok betimsel ve deneysel çalışma bulunmaktadır. $\mathrm{Bu}$ çalışmaların bulgularından yararlanılarak üstün yetenekli öğrencilerin aile içindeki, sosyal ortamlardaki, sınıftaki ve normal gelişim gösteren öğrencilerle veya kendileri gibi üstün yetenekli akranlarıla birlikte oldukları farklı ortamlardaki sosyal-duygusal ihtiyaçlarının saptanması, sorunlar ortaya çıkmadan önce çözülebilmesini sağlayacaktır (Neihart, 1999). Üstün yetenekli çocukların sosyal-duygusal ihtiyaçlarının ve bunlar yeterince karşılanamadığı zaman ortaya çıkabilecek sorunların neler olduğunu bilebilmek, bu sorunları çözümleyebilmek açısından alandaki uzmanlara 1ş1k tutacaktır. Özellikle insanlık tarihini hemen her çağda ileriye götürmüş ve model olmuş üstün yetenekli bireylerin ruhsal sağlıkları, öncelikli olarak kendilerinin yaşam kalitesine ve daha sonra da çok büyük toplumsal faydalara yol açabileceğinden üstünde önemle durulması gereken bir konudur. Bu amaca yönelik olarak yazımızın bundan sonraki bölümlerinde öncelikle üstün yetenekli çocuk ve ergenlerin yaşadığı çoğu sosyal-duygusal sorunun altında yatan eş zamanlı olmayan gelişim konusu açıklanacak, daha sonrasında da bu grupta gözlenen belli başlı sosyal-duygusal sorunlara değinilecektir.

\section{Üstün Yetenekli Çocuklarda Eş Zamanlı Olmayan Gelişim}

Üstün yetenekli çocukların bilişsel, duygusal ve motor gelişimlerinin hızı ve derecesi çoğunlukla farklı düzeylerde gerçekleşir. Sıklıkla görülen gelişimdeki bu dengesizliğe "eş zamanlı olmayan gelişim" (asynchronous development) adı verilmiştir (Terassier, 1985). Robinson ve Noble'a göre üstün yetenekli çocuğun zeka seviyesi arttıkça eş zamanlı olmayan gelişim gösterme ihtimali de bununla doğru orantılı olarak artmaktadır (Akt. 
Silverman, 1994). Üstün yetenekli çocuklar zihinsel gelişimleri açısından akranlarından önde olmalarına karşın sosyal-duygusal ve fiziksel gelişimde bu durumu gösteremeyebilirler. Örneğin yedi yaşındaki üstün yetenekli bir çocuk integral hesapları yapabiliyorken oyun bahçesinde beş yaşında bir çocuk gibi davranabilir. Onbeş yaşındaki üstün yetenekli bir genç, konuşmalarıyla Yunan düşünürlerini birbirleriyle karşılaştırabilecek zihinsel kapasitede bir yetişkin imaji uyandırırken, sosyal ortamlarda kendini pasif hissedip çocukça davranabilir (Delisle ve Lewis, 2003). Roeper'a göre üstün yetenekli çocukların iç dünyaları eş zamanlı olmayan gelişim sebebiyle normal akranlarına göre daha karmaşık ve duyarlıdır. Aşırı düzeydeki farkındalık ile topluma uymada zorluklar ve incinebilirlik gösterebilirler. $\mathrm{Bu}$ tarz gelişim gösteren üstün yetenekli çocuklar sadece düşüncelerinde değil duygu ve davranışlarında da farklıdırlar (Akt. Bickley, 2001).

Fiziksel, sosyal-duygusal ve zihinsel gelişim düzeyleri birbirinden farklı olan üstün yetenekli çocuklar, bulundukları düzeyin gelişim problemlerini yaşayacaklarından, çoklu sorunlarla karşılaşma riski taşımaktadırlar (Silverman, 1997). Üstün yetenekli çocuklar yaşlarından büyük çocuklar gibi düşünürler ve kendilerine büyük çocukların koyduğu tarzda standartlar koyabilirler. Bu da yaşıtları ile aralarında olumsuz ilişkilere sebep olabilir (Akt. Silverman, 1994). Gelişimin belli alanlarda çok hızlı olması, üstün yetenekli çocuklarda karışı duygu ve düşünceler ile yetersizlik hissine sebep olabilmektedir. Bilişsel işlevler yoğun bir şekilde gelişirken duygusal işlevler bunları yakalamakta zorlanabilir ve bu da çocukların içsel çatışmalar yaşamalarına zemin hazırlayabilir (Schuler, 2003). Eş zamanlı olmayan gelişimin bir başka sonucu da onlara kolay gelen görevlerde rahat hareket ederken alışkın olmadıkları veya zor gelen durumlarda hazırlıksız yakalanmaları ve bu sebeple kızgınlık yaşamalarıdır. Aslında eş zamanlı olmayan gelişim gösterenler sadece üstün yetenekliler değildir. Onları diğerlerinden farklı kılan, beceri ve yeteneklerinin çok fazla ilgi çekmesi yani spot altında olmaları sebebiyle sınırlılıklarının da daha belirgin şekilde algilanmasidır (Delisle ve Lewis, 2003).

Alsop (2003) 535 üstün yetenekli çocukla gerçekleştirdiği çalışmada, arşiv kayıtlarını inceleyerek eş zamanlı olmayan gelişimle ilişkilendirilebilecek davranış örüntüleri olarak kaygı, kendini eleştirme, aşırı derecede duyarlı olma, kolayca üzülme ve kolayca kızma davranışı yanında ergenlik döneminde görülebilen depresyonu ortaya çıkarmıştır. Bickley'nin (2001) 5-16 yaş arası üstün yetenekli çocuklarla gerçekleştirdiği araştırmada eş zamanlı olmayan gelişime bağlı olarak bu çocukların sosyal problemler, duygusal incinme ve yüksek derecede duyarlılık gösterdikleri bulunmuştur. Roedell'in (1984) üstün zihinsel becerileri olan çocukların psikolojik incinebilirliklerini araştırdığı çalışmada da eş zamanlı olmayan gelişim 
faktörü önemli bir etken olarak ortaya çıkarılmıştır. Görüldüğü gibi duygusal incinebilirlik çoğu araştırmada eş zamanlı olmayan gelişim sebebiyle bağlantılı olarak ortaya çıkan ortak bir sonuç olarak görülmektedir. Hatch ve Johnson (1988), okulöncesi dönemdeki üstün yetenekli çocuklarla yürüttüğü çalışmada, eş zamanlı olmayan gelişimden kaynaklanan yalnız başına oynama, sürekli olarak akranlarına patronluk taslama/onlara karışma, hayal gücünü aşırı derecede kullanma, başkalarından sürekli ilgi/davet bekleme ile kendi yaşıtlarından oluşan gruplara girmekte zorlanma gibi davranışlar gözlemlemiştir. Roeper ve Webb'in gerçekleştirdiği bir seri çalışmada da üstün yetenekli çocukların bilişsel, duygusal ve sosyal gelişim alanlarında farklı düzeyde ilerlemeler gösterdikleri ve buna bağlı olarak çeşitli sosyalduygusal sorunlar yaşayabildikleri tespit edilmiştir (Akt. Howard, 1994). Bunlar dışında üstün yetenekli çocukların eş zamanlı olmayan gelişim örüntüleriyle bağlantılı olarak yaşadıkları sosyal ve duygusal zorlanmaların derinlemesine anlatıldığı vaka analizi çalışmalarında da nicel yöntemlerle gerçekleştirilmiş çalışmalara benzer uyum sorunlarının ortaya konulduğu görülmektedir (Akin, 2005; Skinner, 2008). Gerçekleştirilen araştırmaların sonuçlarına göre eş zamanlı olmayan gelişimin, üstün yetenekli çocuk ve ergenlerde görülebilecek pek çok sosyal-duygusal soruna temel teşkil edebileceği söylenebilmektedir.

\section{Üstün Yetenekli Çocuklarda Gözlenen Sosyal-Duygusal Sorunlar}

\section{Sosyal İzolasyon (Dışlanma/ Yalnızlık)}

Yalnızlık, kişinin sosyal ve duygusal ilişkilerindeki nitelik ve nicelikten duyduğu tatminsizlik yüzünden oluşan durum olarak tanımlanmaktadır (Young, 1981). Üstün yetenekli çocuk ve ergenlerin akranlarıyla ortak sosyal beklentileri olmasına karşın, arkadaşlık ve yakın ilişkilerde üstün yetenekli olmalarından kaynaklanan problemler ortaya çıkabilmektedir. Üstün yetenekli çocukların diğerlerinin önüne geçip başarılı olmalarını sağlayan özellikleri, aynı zamanda onların akran ve arkadaş gruplarından , sosyal ortamlardan dışlanmalarına, kıskanılarak yalnız bırakılmalarına da sebep olabilmektedir (Helt, 2008). Bu tarz kıskançlıklar üstün yetenekli çocukların kişisel ilişkiler kurup geliştirmelerinde zorluk yaşamalarına sebep olabilir (Plucker ve Levy, 2001). Bunlar dışında ilgi ve yeteneklerdeki farklılıklarla birlikte, iletişim kurmadaki eksiklikler de üstün yetenekli çocukların sosyal ilişkilerde güvensizlik yaşamalarına neden olabilmektedir. $\mathrm{Bu}$ durum yalnızlık ve toplumdan izole olma gibi sonuçlar doğurabilmektedir (Boland ve Gross, 2007). 
Webb ve arkadaşlarına (2007) göre üstün yetenekli çocukların insan ilişkilerinde yaşadıkları sorunların en önemli sebebi eş zamanlı olmayan gelişimdir. Üstün yetenekli çocukların zihinsel gelişimleri bir arada bulundukları gruptan fazlasıyla farklı olduğu için kolaylıkla etiketlenip dışlanabilirler. En basit tanımıyla kendi yaşıtları tarafından kabul edilmek için "fazla farklıdırlar". Üstün yetenekli çocukların fiziksel, zihinsel, duygusal ve sosyal gelişim düzeylerine uyan farklı akran gruplarına ihtiyaçları vardır. Ayrıca yetişkinlerin üstün yetenekli çocuklar için uygun ve yeterli gördügü sosyal ilişki ile üstün yetenekli çocuğun tanımladığı tatmin edici sosyal ilişki arasında büyük farklar olabilir. Üstün yetenekli çocuklar sadece seviyelerine yakın veya benzer ilgi alanlarına sahip olanlarla girdikleri sosyal ilişkilerden zevk alıyor olabilirler. Üstün yetenekli çocukları insan ilişkilerindeki bazı normlara uymaya zorlamak onlarda yeteneklerini ve gerçekte kim olduklarını saklamanın şart olduğu düşüncesini uyandırabilir. Yetişkinler üstün yetenekli çocuğun sosyal beceriye sahip olmadığını düşünseler de buradaki durum çocuğun sosyal becerileri gösterememesi değil, göstermeyi tercih etmemesi olabilmektedir (Akt. Kerr, 2009).

Üstün yetenekli çocukların genellikle normal gelişim özellikleri gösteren akranlarıyla ilişkilerinde dışlandıkları ve yalnız kaldıklarına ilişkin görüşler bulunmakla birlikte, kendi düzeylerindeki akranlarıyla bir arada olduklarında tam tersine çok uyumlu ve sosyal olabilecekleri düşünülmektedir. $\mathrm{Bu}$ düşünceyi destekleyen çalışmalardan biri de üstün yetenekli çocukların zeka düzeyleri arttıkça sosyal katılım davranışlarında değişme olup olmadığını inceleyen Wright'ın (1990) çalışmasıdır. Bu çalışmada yüksek zeka puanına sahip olan çocukların, daha düşük zeka puanına sahip olanlara oranla farklı bir sosyal katılım sergilemedikleri ve üstün zekalı olma derecesinin bu değişken açısından çocuklar arasında fark ortaya koymadığı görülmüştür. Çalışmaya katılan tüm üstün yetenekli çocukların kendi aralarındaki iletişimlerde mümkün olduğunca bir arada olmaya, birlikte oynamaya ve tek başına yapılacak aktivitelerde bile grup oluşturmaya çalıştıkları kaydedilmiştir. $\mathrm{Bu}$ sonuçlar, üstün yetenekli çocukların kendileri gibi üstün yetenekli yaşıtlarıyla bir arada olduklarında sosyal davranışlar gösterip katılımcı olabilecekleri ve sosyal dışlanma riskinin az olabileceği görüşünü desteklemektedir. Douthitt (1992), üstün yetenekli ve normal gelişim gösteren 296 çocukla gerçekleştirdiği araştırmada, gruplar arasında sosyal davranışlar ve uyum davranışı açısından fark olup olmadığını araştırmış ve zeka puanları ile uyum puanları arasında yüksek bir ilişki olduğunu, üstün yetenekli çocukların üstün olmayan akranlarına oranla daha yüksek seviyede uyumlu davranışlar gösterdiklerini bulmuştur. Benzer şekilde uyum ve kendini olumlu şekilde algılamaya 
ilişkin Ciğerci'nin (2006) üstün yetenekli olan ve olmayan Türk ergenlerle gerçekleştirdiği çalışmada da, üstün yetenekli ergenlerde normal akranlarına oranla başkalarının kendisiyle ilgili olumlu düşüncelere sahip olduğu düşüncesinin daha yaygın olduğu bulunmuştur. Konyalığlu ve Varlı'nın (2009) çalışmasında da üstün yetenekli öğrencilerin normal akranlarına oranla daha yüksek oranda sosyal-duygusal uyum gösterdiği bulunmuştur. Üstün yetenekli ergenlerle gerçekleştirilen bir başka araştırmada ise ergenler en fazla reddedildiklerinde, dışlandıklarında, yabancılaşma hissettiklerinde ve bir durumun kontrolü ellerinde olmadığında kendilerini yalnız hissettiklerini belirtmişlerdir (Woodward ve Kalyan-Masih, 1990). Kaiser ve Berndt'in (2004) üstün yetenekli ergenlerle gerçekleştirdiği çalışmada farkedilme ihtiyacı, dişlanma ve yetersiz sevgi, anlaşılma ve sosyal destek düşüncelerinden ortaya çıkan yalnızlık durumu ve depresyon duyguları arasında anlamlı bir ilişki görülmüştür. Hollingworth, üstün yetenekli çocukların sosyal dışlanma ve yalnızlık durumunu en yoğun şekilde 4-9 yaşları arasında yaşadıklarını, buna karşın kendilerine uygun bir eğitim grubuyla çalıştıklarında dışlanmanın ortadan kalktığını vurgulamıştır (Akt. Kerr, 2009). Dauber ve Benbow'un (1990), çok üstün ve orta derecede üstün yetenekli ergenleri sosyal ilişkiler açısından karşılaştırdıkları çalışmada, orta derecede üstün yetenekler gösteren grubun çok üstün yetenekli gruba oranla daha uyumlu sosyal ilişkiler bildirdiği, çok üstünlerin ise kendilerini içe dönük, popüler ve aktif olmayan şekillerde tanımladıkları görülmüştür. $\mathrm{Bu}$ araştırmaya dayalı olarak üstün yetenekliliğin derecesi arttıkça sosyal ilişkiler konusunda risk durumlarının ortaya çıkabileceği akla gelmektedir. Genel olarak çalışmaların sonuçlarına bakıldığında, üstün yetenekli çocuk ve ergenlerin kendileri gibi akranlarıyla birarada olduklarında olumlu sosyal etkileşimler içinde olabildikleri fakat zeka bölümleri arttıça normal populasyondan uzaklaştıkları ve var olan üstünlüklerinin onları çevreye yabancılaşma ve depresyon gibi sorunlara itebileceği görülmektedir.

\section{Mükemmeliyetçilik}

Mükemmeliyetçilik, yüksek standartlara sahip olmayan, başka bir deyişle yeterince mükemmel olmayan hiç bir şeyden mutlu olamamaktır (Strip ve Hirsch, 2000) Mükemmeliyetçilik bu tarz çocukların kişiliklerinin merkezinde yer aldığında kontrol edilmesi zor problemler doğurabilmektedir (Klein, 2006). Mükemmeliyetçiliğe yatkın olan üstün yetenekli çocuklar her zaman aileleri ve öğretmenlerinden "mükemmel" yorumunu almalarını sağlayacak işler ortaya koymak için yoğun çaba gösterirler. Aynı zamanda üstün performans gösterme konusunda yetenekli olduklarından dolayı her zaman tüm sınıfın önünde veya aile içinde mükemmel işler çıkarmaya 
çalışabilirler. Gösterdikleri bu aşırı çaba zamanla onlara zarar vermeye başlayabileceğinden üstün yetenekli çocuklarda mükemmeliyetçilik davranışları dikkatle izlenmesi gereken bir konudur (Delisle ve Lewis, 2003; Seatter, 2001).

Üstün yetenekli çocuklarla çalışan öğretmenler, öğrencilerinde çoğunlukla mükemmeliyetçilik özellikleri gördüklerini fakat bu özelliği yüksek kişisel standartlar olarak $\mathrm{m} 1$ yoksa uyumsuzluk olarak $\mathrm{m} 1$ adlandıracaklarını bilemediklerini belirtmişlerdir (Parker ve Adkins, 1995). Baska'nın belirttiğine göre mükemmeliyetçi özellikler gösteren üstün yetenekli çocuklar, görevleri mükemmel derecede yapabilmek için çok fazla enerji sarfetmekle birlikte kendileri veya etraflarındaki kişiler hata yaptıklarında bundan çok rahatsız olurlar. Mükemmeliyetçiliğin sonucu olan aşırı korku ve kaygı da ayrıca üstün yetenekli çocuğun gelişimini engelleyip suçluluk duygusuna sebep olabildiği gibi, çocuğun serbest keşifler yapmasının önüne geçerek gelişimini yavaşlatabilir (Akt. Koshy, 2002).

Üstün yetenekli çocukların normal gelişim gösteren yaşıtlarına oranla daha fazla mükemmeliyetçi özellikler gösterip göstermediğini araştıran Kramer (1988) hem üstün yetenekli hem de normal gruplarda kendini suçlayıcı tarzda davranış örüntüsü gösteren ergenlerin diğerlerine oranla daha kaygılı ve mükemmeliyetçi oldukları ve genel olarak üstün yetenekli grubun daha fazla mükemmeliyetçi özellikler gösterdiğini bulmuştur. Roberts ve Lowett (1994) da üstün yetenekli ergenler üzerinde gerçekleştirdikleri çalışmada benzer şekilde üstün yetenekli grubun normal ve akademik olarak başarılı akranlarına oranla daha yüksek mükemmeliyetçilik özellikleri gösterdiğini bulmuştur. Türk ergenler üzerinde gerçekleştirilen Misırlı-Taşdemir'in (2003) çalışmasında üstün yetenekli öğrencilerde sınav kaygısının duyuşsallık ve kuruntu boyutları ile mükemmeliyetçilik arasında pozitif yönde anlamlı bir ilişki bulmuştur. Silverman'ın çalışmasında ise üstün yetenekli çocukların ailelerinin çocukları konusunda en sı belirttikleri kişilik özelliklerinin mükemmeliyetçilik ve eleştirilmeye karş1 güçlü şekilde tepki verme olduğu görülmüştür (Akt. Rogers 1986). Toy'un (2009) araştırmasında, çocuklardan en çok ve en az sahip oldukları kişilik özelliklerini tanımlamaları istendiğinde mükemmeliyetçilik özelliği çoğunluk tarafından en az belirtilen özelliklerden biri olarak ortaya çıkmıştır. Parker ve Mills'in (1996) çalışmalarında ise üstün yetenekli ve normal gelişim gösteren çocuklar arasında mükemmeliyetçilik derecesi açısından anlamlı bir fark görülmemiştir. $\mathrm{Bu}$ araştırmaların sonuçları, üstün yetenekli çocuklarda görülen mükemmeliyetçiliğin normal populasyona oranı konusunda çelişkili sonuçlar olduğunu göstermektedir. 
$\mathrm{Bu}$ noktada mükemmeliyetçiliğin genel olarak olumlu/uyumlu mükemmeliyetçilik ve olumsuz/uyumsuz mükemmeliyetçilik olarak iki ayrı grupta incelendiği araştırmalar, konunun özünü anlamamızda daha faydalı olacaktır. Mükemmeliyetçiliği uyumlu ve uyumsuz olarak ikiye ayıran Rice, Ashby ve Slaney (1998), uyumlu mükemmeliyetçilerin motivasyonlarının ve başarı oranlarının yüksek olduğunu, uyumsuz mükemmeliyetçilerin ise kaygı ve depresyona girme oranının yüksek, benlik algılarının ise düşük olduğunu vurgulamaktadırlar. Üstün yetenekli çocukların olumlu/uyumlu mükemmeliyetçi özellikler göstermeye daha yatkın olduklarını tespit eden bazı araştırmalar bulunmaktadır. Örneğin, normal gelişen ve üstün yetenekli ergenlerin mükemmeliyetçilik eğilimlerini inceleyen Lo Cicero ve Ashby (2000), üstün yetenekli ergenlerin uyumlu mükemmeliyetçilik puanlarının normal akranlarından yüksek olduğunu, yani "kendilerine başarılı olmak için yüksek kişisel standartlar koyduklarını", bununla birlikte yine üstün yetenekli ergenlerin uyumsuz mükemmeliyetçiliği yani "kişinin standartları ile gösterdiği performans arasındaki farklılık sonucu artmış sıkıntılı durum"u pek fazla yaşamadıklarını bulmuşlardır. Parker (1997), zihinsel alanda üstün yetenekli çocuklar üzerinde yaptığı araştırma sonucunda, çocukların yarıya yakınının (\% 41.7) sağlıklı mükemmeliyetçilik özellikleri gösterdiğini ortaya koymuştur. Schuler'in (2000) nitel ve nicel veri toplama teknikleriyle gerçekleştirdiği çalışmada ise, mükemmeliyetçilik davranışının normal kabul edilebilecek duygu ve davranışlardan nörotik denilebilecek tam tersi yöne kadar oldukça geniş bir yelpazede görülebildiği, bununla birlikte örneklemdeki üstün yetenekli öğrencilerin büyük çoğunluğunun (\%87.5) mükemmeliyetçi özellikler gösterdiği, yarısından fazlasının (\%58) olumlu mükemmeliyetçilik özelliği gösterirken, bir kısmının ise (\% 29.5) nörotik oranda, yani olumsuz mükemmeliyetçilik özelliği gösterdiği bulunmuştur. Bransky (1989), mükemmeliyetçi özellikler gösteren üstün yetenekli lise öğrencilerinin kendilerini davranışlarının sonuçları konusunda sorumlu hissettikleri için akademik çabalarının sonuçları hakkında da doğal olarak daha fazla sorumluluk aldıklarını bulmuş̧tur. Bunun dışında yüksek oranda akademik mükemmeliyetçilik sergileyen öğrencilerin akademik başarılar dışında yaşamın diğer alanlarında da uzmanlaşmak ve başarılı olmak için yoğun çaba harcadıkları görülmüştür. Dixon, Lapsley ve Hanchon'un (2004) üstün yetenekli 141 lise öğrencisiyle gerçekleştirdiği çalışmanın sonuçlarına göre ruh sağllğı, uyum ve başa çıkma becerileri açısından öğrencilerin önemli bir kısmının olumlu/uyumlu mükemmeliyetçilik gösteren grupta yer aldıkları görülmüştür. $\mathrm{Bu}$ çalışmalar, sonuçları açısından üstün yetenekli çocukların mükemmeliyetçiliği her zaman kendilerine zarar verecek şekilde uygulamadıklarını göstermektedir. 
Bununla birlikte yukarıdaki araştırma sonuçlarından farklı olarak mükemmeliyetçiliğin aşırı görüldüğü durumlarda üstün yetenekli çocuklara zarar verdiğini gösteren sonuçlar da bulunmaktadır. Örneğin, Bencik'in (2006) çalışmasında üstün yetenekli ergenlerin mükemmelliyetçiliklerinin yüksek olduğu görülmüş, benlik kavramı ve mükemmelliyetçilikleri arasındaki ilişki incelendiğinde, mükemmelliyetçilik arttıkça benlik saygısının azaldığı bulunmuştur. Üstün yetenekli kız çocuklar üzerinde Kline ve Short'un (1991) gerçekleştirdikleri çalışmada da benzer şekilde okul yıllarında süregiden mükemmeliyetçilik davranışlarının, kendine güven ve kendine sayg1 duymayı azalttığı görülmüştür. Chan (2003), üstün yetenekli çocukların uyum sorunlarıyla ilgili araştırmasında benzer şekilde mükemmeliyetçiliği önemli bir sorun olarak tespit etmiştir. Seatter (2001) üstün yetenekli ergenlerin mükemmeliyetçiliğe bakış açısını incelediği araştırmasında, katılımcıların çoğunluğunun çok yüksek başarı standartlarına sahip olduklarını bulmuş ve başarı beklentisinin sadece ergenlere ait olmadığını, bunun, aileleleri, öğretmenleri ve akranları tarafindan da çok güçlü şekilde empoze edildiğini ortaya koymuştur. Orange'ın (1997) çalışması ise üstün yetenekli ergenlerde olumsuz mükemmeliyetçilik eğiliminin oldukça fazla olduğunu göstermektedir. Bu araştırmalardan çıkan sonuçlar, üstün yetenekli çocuklarda mükemmeliyetçiliğin derecesinin dengede tutulmasının gerekliliğini ve olumsuz mükemmeliyetçilik özelliklerinin yerini olumlu mükemmeliyetçilik özelliklerinin almasının önemini bizlere hatırlatmaktadır.

\section{Stres}

Stres, kişinin kendisi veya çevresi tarafindan oluşturulmuş beklenti ve istekler karşısında yoğun şekilde yaşadığı her türlü fiziksel, duygusal ve zihinsel tepkiler için kullanılan bir terimdir. Bir görevi son dakikada yetiştirmeye çalışmak kadar heyecanlı bir tenis maçı seyretmek de aynı oranda stresli olabilmektedir (Kaplan, 1990). Üstün yetenekli olmak her zaman için stres yaşamayı gerektirmese de, üstün özellikler taşımak çeşitli durumlarda strese yol açabilir. Bunların farkında olmak, sorunları önceden görüp üstün yetenekli çocukların desteklenmesini sağlayacaktır (Delisle ve Lewis, 2003; Peterson, 2009). Üstün yetenekli çocukların stres yaşama sebeplerinden biri duyarlılıkları, diğeri ise mükemmel olmaya çalışmalarıdır. Bunun dışında akran ve ailelerinin başarılarını önemsememeleri de stres yaratabilmektedir (Kaplan ve Geoffroy, 1993). Zaman sinırlamasının olmas1 veya uygun kaynakların bulunmaması, belli bir konudaki öğrenme heyecanını devam ettirmeyi isteyen veya yenilik peşindeki yaratıcı ve üstün yetenekli çocuklar açısından stres yaratabilir. Üstün yetenekli çocuklar 
genellikle çok meraklıdırlar ve çok soru sorarlar. Fakat bu sebeple öğretmenlerinin zamanlarını fazlasıyla aldıklarını düşünerek kendilerini strese sokabilirler. Bunun dışında ailesi, öğretmenleri ve akranlarının kendisinden yüksek beklentilerinin olması da üstün yetenekli çocuk üzerinde yoğun bir bask1 ve stres oluşturabilir. Üstün yetenekli çocuklar zekaca çok parlak olma etiketiyle yaşamaları sebebiyle kendilerini baskı altında hissedip, ihtiyaçları olsa bile yardım istemeyebilirler. Ayrıca yalnız çalışmaktan memnun olan üstün yetenekli bir çocuk sosyalleşmenin ve grup halinde çalışmanın bir kural olduğunu düşünürse bu düşünce de kendisini yetersiz hissetmesine ve stres yaşamasına sebep olabilir (Kaplan, 1990; Koshy, 2002; Üstün, 2004).

Alanyazında üstün yetenekli çocuklar ve stres konusunu ele alan çeşitli araştırmalar bulunmaktadır. Bunlardan biri olan Peterson, Duncan ve Canady'nin (2009) çalışmasında üstün yetenekli çocukların yaşadıkları stresin kaynaklarının genellikle okul değişiklikleri, akademik baskılar, aile, arkadaşlar ve gelecekle ilişkili kararlar olduğu görülmüştür. Grossberg'in (1985) 7-11 yaş arası 83 üstün yetenekli çocukla gerçekleştirdiği çalışmada, çocukların zeka ve kaygı düzeyleri arasında negatif ilişki olduğu görülmüştür. Yani zeka seviyesi yükseldikçe kaygı düzeyi düşmektedir. Preuss ve Dubow (2004), üstün yetenekli çocukların strese cevap vermede normal akranlarına gore problem çözme stratejilerini daha fazla kullandıklarını bulmuştur. Karnes ve Oehler-Stinnet (1986), üstün yetenekli ergenlerle gerçekleştirdikleri çalışmada geçmişte yaşanmış ve yaşanmakta olan stresin derecesinin intihar fikirleri oluşturmada etkili olduğunu ortaya çıkarmışlardır. Bu grupta özellikle performans baskısı, başarılı olma isteği, sosyal statü ve kariyer amaçları en stresli yaşantılar olarak ortaya çıkmıştır. Ferguson'un (1981) gerçekleştirdiği bir diğer araştırmada üstün ve normal gelişim gösteren 96 ergene uygulanan anket sonucunda üstün yetenekli ergenlerin normal ergenlere oranla daha az stresli yaşantı geçirdikleri belirtilmektedir. Üstün yetenekli çocukların yaşayabilecekleri sosyalduygusal sorunların neler olduğunu öğrenebilmenin bir başka yolu da ailelerdir. Bu konuda yapılan kapsamlı bir çalışmada üstün yetenekli çocukların sosyal-duygusal ihtiyaçlarına hizmet veren bir rehberlik merkezine gelen 120 aileye danışmanlık görüşmeleri öncesinde uygulanan tipik bilgi alma formu sonuçlarına göre, çocukları büyüdükçe ailelerin daha fazla oranda okulla ilgili endişe/stres hakkında danışmanlık istedikleri görülmüştür (Yoo ve Moon, 2006). Üstün yetenekli çocuklardaki stres konusunda gerçekleştirilen araştırmalar, birbiriyle çelişen farklı sonuçlar ortaya koymaktadır. Stresin yoğunluğu ve süresine bağlı olarak psikolojik rahatsızlıklar ortaya çıkabileceği, buna karşın uygun problem çözme ve başa çıkma becerileri kullanıldığında stresin olumsuz etkilerinin azaltılabileceği 
de görülmektedir. Üstün yetenekli çocuklar büyüyüp ergenlik dönemine ulaştıklarında yaşanılan stresin de birikimli olarak artabileceği göz önüne alınarak, stresle baş etmede uygun becerilerin erken yaşta öğretilmesi faydalı olacaktır.

\section{Depresyon}

Depresyon, mutsuzluk, çaresizlik ve ümitsizliğin eşlik ettiği, kişinin beden ve ruh sağlığını etkileyen duygu durumu ve tıbbı bir rahatsızlık olarak tanımlanmaktadır. Üstün yetenekli ve normal gelişen çocuklar arasındaki farklardan olan yaşamla ilgili endişe ve soruların ortaya çıktığı dönem, üstün yeteneklilerde daha erken yaşlarda oluşabilmektedir (Reis ve Renzulli, 2004). Webb ve arkadaşlarına (2007) göre tipik gelişim gösteren ergenlerde bu tarz sorularla ilgilenmek normal gelişimin parçasıyken, eş zamanlı olmayan gelişimleri sebebiyle üstün yetenekli çocuklarda bu tarz endişe ve sorular 8-9 yaşlarında ortaya çıkabilmektedir. Özellikle anlamsız bir dünyada yaşadıklarını düşünüp bunu değiştirmeye yetecek güce sahip olmadıklarını farkettiklerinde yaşadıkları depresyona varoluşsal depresyon denilmektedir. Depresyon yaşama olasılığı olan üstün yetenekli çocukların özellikleri "dışlanmışlık/diğer insanlar tarafından yalnız bırakılmışlık hissine sahip olma, varoluş problemleriyle, dinsel ve etik tartışmaları çok ciddiye alma ve aşırı sorgulama," olarak tanımlanmıştır (Akt. Weisse, 1990).

Üstün yetenekli çocuk ve ergenlerin normal yaşıtlarına göre depresyon yaşama sıklığına ilişkin çelişkili görüşler bulunmaktadır. Bunlardan bazıları çeşitli sebeplerden dolayı üstün yeteneklilerin depresyona yatkın olduklarını öne sürmüşlerdir. Örneğin Weiss (1990), üstün yetenekli çocukların kendileri ve başkaları için koydukları yüksek standartlar ve yalnızlık sebebiyle depresyona yatkın olabileceklerini, bunun dişında başarılı olmaları için aşırı baskı gören ve anne babalarının beklentilerini karşılayamamaktan dolayı güvenlerini yitiren üstün yetenekli çocuklarda depresif davranışlar görülebileceğini belirtmiştir. Neihart ve Olenchak'ın çalışmasında edebiyat/yazı veya görsel sanatlarda yaratıcı olan çocukların daha fazla depresyona girme riskleri olduğunu gösteren çalışmalar bulunmaktadır (Akt. Helt, 2008). Bazı üstün yetenekli ergenlerin utanmaları veya başkalarını koruma istekleri sebebiyle yaşadıkları depresyonu saklayabildikleri bulunmuştur (Jackson ve Peterson, 2003). Bu durum üstün yeteneklilerdeki depresyonun sıklığının ve derecesinin anlaşılmasını zorlaştırıcı bir etken olmaktadir.

Üstün yetenekli çocuklarda depresyonun görülme sıklı̆̆ını araştıran çalışmalarda genellikle üstün yetenekli çocuk ve ergenlerin normal akranlarına benzer seviyelerde depresyon düzeyleri gösterdiği bulunmuştur 
(Baker, 2004; Bartell ve Reynolds, 1986; Neihart, 1991). Bartell ve Reynolds (1986), dördüncü ve beşinci sınıftaki üstün yetenekli ve normal 145 öğrenciyi depresyon ve kendine güven düzeyleri açısından karşılaştırdığı çalışmalarında, gruplar arasında her iki konuda da anlamlı bir fark bulamamışlardır. Benzer şekilde Baker (2004) da üstün yetenekli grup ile normal akranları arasında depresyon yaşama düzeyi açısından anlamlı bir fark olmadığını açıklamıştır. Neihart (1991), üstün yetenekli ve ortalama yetenekli ergenlerle gerçekleştirdiği araştırmada hiç bir grupta müdahale gerektirecek oranda depresyon eğilimi görememiştir. Ek olarak üstün yetenekli grubun ruh sağlığı kriterleri açısından diğer gruba oranla daha yüksek puanlar aldığ1 görülmüştür. Kaiser, Berndt ve Stanley'nin (1987) üstün yetenekli ergenlerdeki depresyon üzerine yürüttükleri araştırma diğer çalışmalarla benzer sonuçlar bulmuş, yani üstünlerin akranlarından farklı bir depresyon düzeyi göstermediğini, bununla birlikte üstün yetenekliler grubunun yaklaş1k \%14'lük kesiminde tüm ergen nüfusunda görülebilecek miktarda depresyon görüldüğünü kaydetmişlerdir. Ciğerci (2006) Türk ergenlerle gerçekleştirdiği çalışmada yukarıdaki bulgulardan farklı şekilde üstün yetenekli ergenlerin normal yaşıtlarına göre depresyon belirtileri taşıma olasılığının daha fazla olduğunu görmüştür. $\mathrm{Bu}$ sonuç kültürel farkların üstün yetenekli çocuklardaki depresyon konusunda farklı görünümler ortaya çıkarabileceğini göstermektedir. Üstün yetenekli çocukların normal akranlarına oranla depresyon yaşama ihtimalleri ve dereceleri konusunda yapılan araştırma sonuçları, üstün yetenekliler lehine olumlu bir tablo ortaya çıkarmaktadır. Fakat bu özel grupta gelişebilecek depresyonun önüne geçebilmek için depresyonun nedenleri, farklı üstün yetenekli gruplardaki görünümleri ve önleme yöntemleri konusunda yapılacak araştırmaların gerekliliği de ortadadır. Üstün yetenekli çocukların yaşayabilecekleri depresyonun tedavisinde Bilişsel Davranışçı Terapiler veya Biblioterapi gibi yöntemlerin kullanılması önerilmektedir (Kerr, 1991).

\section{İntihar}

Webb ve arkadaşlarına (2007) gore intihar davranışı genellikle insanların başa çıkamadıklarını hissettikleri stres yaratan durumlar sebebiyle oluşmaktadır. Genellikle 14 yaş altı üstün yetenekli çocukların intihar hakkında konuşabildiği, fakat intihar teşebbüsünün ve kendine zarar verici davranışların çoğunlukla 14-17 yaşları arasında belirdiği gözlenmiştir. Bunun sebebi ise ergenliğin normal baskılarının ve kimlik arayışının en yoğun yaşandığı dönemlerin bu yaşlara denk gelmesidir. Okuldaki intihar teşebbüslerinin yaratıcı yeteneği bulunan, öğrencilerini ulaşılması zor kriterlerle seçen ve rekabete dayalı ortamlar yaratan okullara devam eden ve 
okul başarısı son zamanlarda ani düşüşler gösteren gençlerde daha s1k görüldüğü kaydedilmiştir (Akt. Weisse, 1990). Delisle ve Lewis, üstün yetenekli ergenlerde intihar üzerine yaptıkları çalışmalarda sebebin aşırı duyarlılıklar olduğunu savunmaktadırlar. İntihara teşebbüs eden ergenler arasında üstün yetenekli olanların çabalarının ölümle sonlanma ihtimalinin yüksek olmasının sebebi olarak, intiharı kesin başarıya ulaşacak şekilde planlamaları gösterilmektedir (Akt. Kerr, 1991).

Üstün yetenekli çocuk ve ergenlerde, normal populasyona oranla intihar davranışının sıklı̆ğıda kesin yargılara varacak sayıda kanıtlanmış bilgi bulunmamaktadır (Reis ve Renzulli, 2004). Bununla birlikte, gerçekleştirilen araştırmaların gözden geçirilmesi gelecekteki çalışmalara 1 şı tutması açısından önemlidir. Örneğin, intihar oranlarında yazarlık ve edebiyatla ilgilenen, yüksek derecede yaratıcılık yeteneği olan üstün yetenekli gençlerin normal gruba göre anlamlı farklılıklar gösterdiği belirtilmiştir (Neihart, 1991). Üstün yetenekli ve normal gelişim gösteren ergenlerin intihara ilişkin düşüncelerini inceleyen pek çok araştırmacı bu gruplar arasında anlamlı farklar bulamamışlardır (Baker, 2004; Cross, Cassady ve Miller, 2006; Hayes, 1991). Üstün yetenekli ergenlerin intihar eğilimleri ve gerçekleşmiş intihar vakaları konusundaki bilgiler zamanla artmaktadır. Buna karşın bulunduğumuz noktada, normal gruba oranla üstün yeteneklilerde intihar düşünce ve eylemlerinin sıklığının daha fazla veya az olduğu söylenememektedir (Gust-Brey ve Cross, 1999). Uyarı işaretleri ve riskler karşısında duyarlı olmak, intihar girişimlerinin önüne geçmede en önemli adımlardandır. Üstün yetenekli gençlerde intihar etme niyetinin belirtilerini anlayabilmek ve bunun önüne geçebilmek için ailelerin ve eğitimcilerin gençlerdeki sözel ve davranışsal ipuçlarını tanıyabilmede çok iyi birer gözlemci olmaları ve intihar konusunda şüphelendiklerinde zaman geçirmeden uzman yardımı aramaları gereklidir (Weisse, 1990).

\section{SONUÇ VE ÖNERILLER}

Üstün yetenekli çocukların sosyal-duygusal sorunları konusunu mümkün olduğunca geniş bir bakış açısıyla ele almaya çalıştı̆̆ımız bu yazıyla, konunun derinliği ve genişliği gözler önüne serilmeye çalışılmıştır. $\mathrm{Bu}$ alanda gerçekleştirilen araştırmaların sonuçlarını toparlayarak konuyla ilgili bir çerçeve çizmek istediğimizde, bazı noktaların ön plana çıktığını görmekteyiz. Bunlardan ilki, incelediğimiz bazı sosyal-duygusal sorunlarda üstün yeteneğin tipinin (yazarlık/edebiyat alanında üstün yetenek gibi) ve derecesinin (orta derece ve çok yüksek derece üstün yetenekli) araştırmaların sonuçlarını etkiliyor gibi görünmesidir. Buradan, özellikle üstün yetenekli çocukların normal populasyonla aralarındaki farkın çok fazla 
açıldığ 1 ve ortak noktaların azaldı $\breve{g} 1$ durumlarda psikolojik sağlığın korunması için gereken ek tedbirlerin alınmasının önemi ortaya çıkmaktadır. Bir başka önemli nokta ise, çocukla ilgili her konuda olduğu gibi aile faktörünün ve üstün yetenekli çocuğun kişilik yapısının sosyal-duygusal sorunların ortaya çıkışında önemli değişkenler olarak karşımıza çıkmasıdır. Dolayısıyla üstün yetenekli çocukların sosyal-duygusal sağlıklarının temelini teşkil eden sac ayağının aile, çocuğun kişiliği ve sahip olduğu zeka düzeyinden oluştuğunu söyleyebiliriz. Bu görüşe ek olarak uygun ev ve okul ortamlarında üstün yetenekli çocukların en az normal gelişen akranları kadar, hatta çoğu durumda onlardan daha fazla uyumlu oldukları ve olumlu kişilik özellikleri geliştirdikleri de söylenebilir.

Üstün yetenekli çocukların sosyal-duygusal gelişimlerini desteklemek ve ortaya çıkabilecek risk faktörlerinin önüne geçebilmek için alınabilecek pek çok önlem bulunmaktadır. Bu noktada sosyal anlamda güçlü oldukları özellikleri ön plana çıkarmak ve yapabildiklerine odaklanmak sağlıklı kişilik oluşturmalarını sağlayacak en önemli adımlar olacaktır. Üstün yetenekli çocukların ileri seviyedeki bilişsel yeterliklerinin, aşırı duyarlılıklarının ve eş zamanlı olmayan gelişim örüntülerinin bazı sosyal-duygusal sorunlara yol açabileceği bilinmekle beraber, bu çocukların problem çözme becerileri, ahlaki gelişmişlikleri, okul dişı ilgileri ve başarılarından edindikleri mutluluk sayesinde bu tarz sorunlara karşı daha dayanıklı olabilecekleri söylenebilir. Gerekli olduğu durumlarda üstün yetenekli çocuklara etkili çalışma ve zaman yönetimi teknikleri öğretilerek, stresin olumsuz etkilerinin oluşmasının önüne geçilebilmektedir (Kaplan ve Geoffroy, 1993). Stres kaynakları hakkında uzman bir kişiyle konuşmaları ve böylece stresin etkileri hakkında farkındalıklarını arttırmaları da sağlıklı bir yaşam sürdürmelerinde etkili olabilecektir (Kaplan, 1990). Üstün yetenekli çocukların kolayca kavrayamadıkları konuları aynı normal gelişim gösteren çocuklar gibi “öğrenmeleri” gereklidir. Bu nokta göz ardı edilmeden onlara zor gelen konularda rehberlik ederek kendi güçlü ve zayıf yönlerini tanımaları sağlanmalı, kendilerini geliştirdiklerinde daha gerçekçi bir benlik alg1s1 oluşturabilecekleri farkettirilmelidir (Kerr, 2009). Karar verme seçeneklerini kullanma, gerektiğinde geri çekilme, destek alma ve verme gibi başa çıkma mekanizmalarının kullanımı da sosyal-duygusal sorunların üstesinden gelmede kullanılabilecek yöntemlerdendir (Bickley, 2001).

Aileler için üstün yetenekli çocuklarının akademik olarak başarılı olduğu alanları ve diğer yeteneklerini iyi analiz edebilmek çok önemlidir. Başarısızlık sorunu karşısında okul ve öğretmenlerle işbirliği yaparak sorunun temelinde yatan nedenleri iyi anlamak çözümü kolaylaştıracaktır (Kerr, 2009). Üstün yetenekli çocuklardaki mükemmeliyetçilik eğilimlerine karşın, yapılan işlerdeki asıl kaliteyi oluşturan şeyin ne olduğuna yönelik 
bakış açısı kazanmaları konusunda rehberlik etmek ve yanlışlar yapmanın öğrenme sürecinin bir parçası olduğunu anlatmak da çok faydalı olacaktır. Üstün yetenekli çocukların performanslarını gösterebilecekleri alanlar belirlenip, üstlerindeki ev ödevi baskısı azaltılarak onlara faydası olmayan görevlerden muaf tutulmaları sağlanabilir. Günlük tutup duygularını ve korkularını yazarak ifade etmeleri, çeşitli spor ve sanat uğraşları edinerek yaşadıkları stresi boşaltmaları desteklenebilir. Sorunlarını tartışabilecekleri ve duygularını güvenli bir ortamda ifade edebilecekleri duygusal destek grupları oluşturmak da faydalı bir başka yöntemdir. Üstün yetenekli çocukların işlenen konuya karşı ilgileri yoksa derinleştirme, zenginleştirme gibi yöntemler kullanıp çok çeşitli uyaran, materyal ve firsatlar sunulabilir (Delisle ve Lewis, 2003). Sonuç olarak üstün yetenekli çocuklar, sorun çözme becerileri, okul dışı ilgileri ve duygusal olgunluklarını da kullanarak üstünlüklerinden kaynaklanan olumlu özelliklere yoğunlaştıklarında, Neihart'ın da belirttiği gibi eş zamanlı olmayan gelişim sorunlarıly başa çıkabilecek güce ulaşabileceklerdir (Akt. Reis ve Renzulli, 2004). Üstün yetenekli çocuklarla çalışan profesyonellerin bu çocukların dahil olduğu grubun sosyal ve duygusal özellikler açısından oldukça heterojen olduğunu bilmeleri de konunun çok önemli bir başka boyutudur. Dolayısılyla danışmanlık ve rehberlik çalışmalarında öncelikle çocukların içinde bulundukları şartların detaylı bir analizi ve değerlendirmesi yapılmalı, daha sonra çocuk ve aileyle yapılan görüşme ve gözlemler sonucunda harekete geçilmelidir (Moon, 2007). Üstün yetenekli çocukların sosyal-duygusal özellikleri ile kişisel özelliklerinin çocukla ilgilenecek uzmanlar tarafindan çok iyi biliniyor olması şarttır.

Yabancı alanyazında, üstün yetenekli çocukların sosyal-duygusal sorunları ve bunların çözüm yolları konusunda uzun süredir pek çok çalışma yapılmaktadır. Ülkemizde de bu konuda özellikle son yıllarda artan sayıda araştırma gerçekleştirilmiştir. Bunlar arasında sosyal-duygusal sorunlara yoğunlaşanlar olmasına karşın, konunun değişik boyutlarını farklı yaş grupları ve üstün yeteneklilik türlerinde inceleyen araştırmalar oldukça azdır. Özellikle ülkemizdeki üstün yetenekli çocukların karşılaştıkları değişik sosyal-duygusal sorunların ve olası çözüm yollarının neler olabileceğine ilişkin daha derin ve kültürel etkiyi göz önüne alan incelemeler yapılması gereklidir. Sadece üst sosyo-ekonomik düzeydeki iyi eğitimli grupla değil, her türlü grupla gerçekleştirilecek uzun süreye yayılmış boylamsal araştırmalar kendi kültürümüzde üstün yetenekliliğin boyutlarını anlamamızda zengin veriler ortaya koyabilecektir. Sonuç olarak, toplumları ileri götürmede itici güç olmuş olan üstün yetenekli çocukların, öncelikle kendi mutluluklarını ve ruh sağlıklarını gerçekleştirebilen bireyler olarak yetişmeleri en önemli amaçlarımızdan biri olmalıdır. 


\section{KAYNAKLAR}

Ackerman, C. (1997). Identifying gifted adolescents using personality characteristics: Dabrowski's overexcitabilities.Roeper Review, 19(4), 229-236.

Akin, C. A. (2005). Academic asynchrony. Gifted Child Today, 28(2), 60.

Alsop, G. (2003). Asynchrony: Intuitively valid and theoretically reliable. Roeper Review, 25(3), 118-127.

Baker, J. A. (2004). Depression and suicidal ideation among academically talented adolescents. In S. Moon (Ed.), Social Emotional Issues, Underachievement and Counseling of Gifted and Talented Students (pp. 21-31). USA: Corwin Press and National Association for Gifted Children.

Bartell, N. P., \& Reynolds, W. M. (1986). Depression and self-esteem in academically gifted and nongifted children: A comparison study. Journal of School Psychology, 24, 55-61.

Bencik, S. (2006). Üstün yetenekli çocuklarda mükemmeliyetçilik ve benlik algısı arasındaki ilişkinin incelenmesi. Yayımlanmamış yüksek lisans tezi, Hacettepe Üniversitesi, Ankara.

Bickley, N. Z. (2001). The social and emotional adjustment of gifted children who experience asynchronous development and unique educational needs.Unpublished dissertation, University of Connecticut.

Boland, C. M., \& Gross, M. U. M. (2007). Counseling highly gifted children and adolescents. In S. Mendaglio \& J. S. Peterson (Eds.), Models of counseling gifted children, adolescents, and young adults (pp. 153199). USA: Prufrock Press.

Bransky, P. S. (1989). Academic perfectionism in intellectually gifted adolescents: The roles of attribution, response to failure, and irrational beliefs. Unpublished dissertation, University of Kansas.

Chan, D. W. (2003). Adjustment problems and multiple intelligences among gifted students in Hong Kong: The development of the Revised Student Adjustment Problems Inventory. High Ability Studies, 14, 4154.

Ciğerci, Z. C. (2006). Üstün yetenekli olan ve olmayan ergenlerde benlik saygisl, başkalart tarafindan algllanma ve psikolojik belirtilerin karşıllaştırılması. Yayımlanmamış yüksek lisans tezi, Sakarya Üniversitesi.

Cross, T. C., Cassady, J. C., \& Miller, K. A. (2006). Suicide ideation and personality characteristics among gifted adolescents. Gifted Child Quarterly, 50(4), 295-306. 
D'souza, D. M. (1994). An investigation study of the relationship between intellectual ability and psychosocial adjustment in early adolescence. Unpublished dissertation, University of Texas, Austin.

Dauber, S. L., \& Benbow, C. P. (1990). Aspects of personality and peer relations of extremely talented adolescents. Gifted Child Quarterly, 34(1), 10-14.

Delisle, J. R., \& Lewis, B. A. (2003). The survival guide for teachers of gifted kids. USA: Barnes and Noble Publishing.

Dixon, F. A., Lapsley, D. K., \& Hanchon, T. A. (2004). An empirical typology of perfectionism in gifted adolescents. Gifted Child Quarterly, 48(2), 95-106.

Douthitt, V. C. (1992). A comparison of adaptive behaviour in gifted and nongifted children. Roeper Review, 14 (3), 149-151.

Ferguson, W. E. (1981). Gifted adolescents, stress and life changes. Adolescence, 6, 246-267.

Freeman, J. (1985). The psychology of gifted children: Perspectives on development and education. Great Britain: John Wiley and Sons.

Gardner, H. (1993). Frames of mind: The theory of multiple intelligences. New York: Basic Books.

Grossberg, I. N. (1985). Relationships between $1 q$ and emotional adjustment in gifted latency age children. Unpublished dissertation. Wayne State University.

Gust-Brey, K., \& Cross, T. C. (1999). An examination of the literature base on the suicidal behaviors of gifted students. Roeper Review 22(1), 2835.

Hatch, J., \& Johnson, L. G. (1988). Guiding the social development of gifted and talented preschoolers. Paper presented at the Annual Conference of the National Association for the Education of Young Children, Anaheim, CA.

Helt, C. A. (2008). The role of $\imath q$ and gender in the social-emotional functioning of adolescents. Unpublished dissertation. University of Northern Colorado.

Howard, D. D. (1994). A naturalistic study of the psychosocial development of highly gifted young girls. Unpublished dissertation, University of Denver.

Jackson, P. S., \& Peterson, J. S. (2003). Depressive disorder in highly gifted adolescents. Journal of Secondary Gifted Education, 14(3), 175-186.

Kaiser, C. F., \& Berndt, D. J. (2004). Predictors of loneliness in the gifted adolescents In S. Moon (Ed.), Social emotional Issues, underachievement, and counseling of gifted and talented students. USA: Corwin Press and National Association for Gifted Children. 
Kaiser, C. F., Berndt, D. J., \& Stanley, G. (1987). "Moral judgement and depression in gifted adolescents". 7th World Conference on Gifted and Talented, Salt Lake City, Utah.

Kaplan, L. S. (1990). Helping gifted students with stress management. In S. Berger (Ed.), Flyer file on gifted students. Reston:VA: Council for Exceptional Children Digest.

Kaplan, L. S., \& Geoffroy, K. E. (1993). Copout or burnout? Counseling strategies to reduce stress in gifted students. School Counselor, 40(4), 247-252.

Karnes, F. A., \& Oehler-Stinnet, J. J. (1986). Life events as stressors with gifted adolescents. Psychology in the Schools, 23(4), 406-414.

Kerr, B. (1991). A handbook for counseling the gifted and talented. USA: American Associaton for Counseling and Development Press.

Kerr, B. (Ed.). (2009). Encyclopedia of giftedness, creativity and talent. California: Sage Publications.

Klein, B. S. (2006). Raising gifted kids:Everything you need to know to help your exceptional child thrive. New York: Amacom.

Kline, B. E., \& Short, E. B. (1991). Change in emotional resilience: Gifted adolescent females. Roeper Review 13, 118-121.

Konyalığlu, A. P., \& Varlı, M. F. (2009). "Üstün ve normal zekalı çocukların sosyal-duygusal uyum düzeylerinin karşılaştırılması". Üstün Yetenekli Çocuklar II. Ulusal Kongresinde sunulan bildiri, Eskişehir.

Koshy, V. (2002). Teaching gifted children: A guide for teachers. London: David Fulton Publishers.

Kramer, H. J. (1988). Anxiety, perfectionism and attributions for failure in gifted and non-gifted junior high school students. Unpublished dissertation, Catholic University of America.

Lo Cicero, K. A., \& Ashby, J. S. (2000). Multidimensional perfectionism in middle school age gifted students: A comparison to peers from the general cohort. Roeper Review, 22(3), 182-185.

McMann, N., \& Oliver, R. (1988). Problems in families with gifted children: Implications for counselors. Journal of Counseling and Development, 66(6), 275-278.

Metin, N. (1999). Üstün yetenekli çocuklar. Ankara: Öz Aşama Matbaacıllk.

Mısırl1-Taşdemir, Ö. (2003). Üstün yetenekli çocuklarda mükemmelliyetçilik, sınav kaygısl, benlik saygısı, kontrol odağl, öz yeterlilik ve problem çözme becerileri arasındaki ilişkinin incelenmesi. Yayınlanmamış yüksek lisans tezi, Karadeniz Teknik Üniversitesi. 
Moon, S. (2007). Counseling issues and research. In S. Mendaglio \& J. S. Peterson (Eds.), Models of counseling gifted children, adolescents and young adults (pp. 7-27). USA: Prufrock Press.

Morelock, M. (1992). Giftedness: The view from within. Understanding Our Gifted, 4(3), 11-15.

Neihart, M. (1991). Anxiety and depression in high ability and average ability adolescents. Unpublished dissertation, University of Northern Colorado.

Neihart, M. (1999). The impact of giftedness on psychological well-being: What does the empirical literature say? Roeper Review, 22(1), 10.

Neihart, M. (2006). Services that meet social and emotional needs of gifted children. In J. H. Purcell \& R. D. Eckert (Eds.), Designing services and programs for high ability learners: A guidebook for gifted education(pp. 112-124). California: Corwin Press.

Orange, C. (1997). Gifted students and perfectionism. Roeper Review, 20(1), $39-42$.

Parker, W. D. (1997). An empirical typology of perfectionism in academically talented children. American Educational Research Journal, 34(3), 545-562.

Parker, W. D., \& Adkins, K. K. (1995). Perfectionism and the gifted. Roeper Review, 17(3), 173-175.

Parker, W. D., \& Mills, C. J. (1996). The incidence of perfectionism in gifted students. Gifted Child Quarterly, 40, 194-199.

Peterson, J. S. (2009). Myth 17: Gifted and talented individuals do not have unique social and emotional needs. Gifted Child Quarterly, 53(4), 280282.

Peterson, J. S., Duncan, N., \& Canady, K. (2009). A longitudinal study of negative life events, stress, and school experiences of gifted youth. Gifted Child Quarterly, 53(1), 34-49.

Plucker, J. A., \& Levy, J. J. (2001). The downside of being talented. American Psychologist, 56(1), 75-76.

Preuss, L. J., \& Dubow, E. F. (2004). A comparison between intellectually gifted and typical children in their coping responses to a school and a peer stressor. Roeper Review, 26(2), 105-111.

Reis, S. M., \& Renzulli, J. S. (2004). Current research on the social and emotional development of gifted and talented students: Good news and future possibilities. Psychology in the Schools, 41(1), 119-130.

Rice, K. G., Ashby, J. S., \& Slaney, R. (1998). Self esteem as a mediator between perfectionism and depression: A structural equations analysis. Journal of Counseling Psychology, 45, 393-398. 
Roberts, S. M., \& Lovett, S. B. (1994). Examining the "F" in gifted: Academically gifted adolescents' physiological and affective responses to scholastic failure. Journal for the Education of the Gifted, 17, 241-259.

Robinson, A., Shore, B. M., \& Enersen, D. L. (2007). Best practices in gifted education: An evidence-based guide. USA: National Association for Gifted Children Prufrock Press.

Roedell, W. (1984). Vulnerabilities of highly gifted children. Roeper Review, 6(3), 127-130.

Rogers, M. T. (1986). A comparative study of developmental traits of gifted and average children. Unpublished dissertation, University of Denver.

Schuler, P. A. (2000). Perfectionism and gifted adolescents. Journal of Secondary Gifted Education, 11(4), 183-196.

Schuler, P. A. (2003). "Gifted kids at risk: Who's listening?" [Online]. Retrieved on 20-March-2010, at URL: http://www.sengifted.org/articles_social/Schuler_GiftedKidsAtRiskW hosListening.shtml

Seatter, D. W. (2001). Adolescents' interaction with giftedness and perfectionism. Unpublished master thesis, Mount Saint Vincent University, Canada.

Şenol, S. (2006). Çocuk ve gençlik ruh sağlığı. Ankara: Hyb Yayıncılık.

Silverman, L. K. (1994). The moral sensitivity of gifted children and the evolution of society. Roeper Review, 17(2), 110-116.

Silverman, L. K. (1997). The construct of asynchronous development. Peabody Journal of Education, 72(3-4), 36-58.

Skinner, W. A. (2008). From headaches to heartaches to healing: Jillian's story. Parenting for High Potential, 6.

Sloat, R. S., \& Hayes, M. L. (1991). "Gifted adolescents attitudes toward suicide". 69th Annual Conference of the Council for Exceptional Children, Atlanta.

Strip, C. A., \& Hirsch, G. (2000). Helping gifted children soar: A practical guide for parents and teachers. Scottsdale: Great Potential Press.

Swanepoel, R. E. (1987). The psychosocial adjustment of gifted adolescents. Unpublished master thesis, University of Pretoria, South Africa.

Terassier, J. C. (1985). Dyssynchrony-uneven development. In J. Freeman (Ed.), The psychology of gifted children: Perspectives on development and education (pp. 265-275). New York: Wiley and Sons.

Toy, R. E. (2009). Characteristics of individuals who are gifted: An analysis of self report scores. Unpublished dissertation, University of Northern Colorado College of Education and Behavioral Sciences. 
Webb, J., Gore, J., Amend, E., \& Devries, A. (2007). A parent's guide to gifted children. Scottsdale, AZ: Great Potential Press.

Weisse, D. E. (1990). Gifted adolescents and suicide. School Counselor, 37(5), 351-359.

Woodward, J. C., \& Kalyan-Masih, V. (1990). Loneliness, coping strategies and cognitive styles of the gifted rural adolescent. Adolescence, 25(100), 977-988.

Wright, L. (1990). The social and nonsocial behaviours of precocious preschoolers during free play. Roeper Review, 12(4), 268-274.

Yoo, J. E., \& Moon, S. M. (2006). Counseling needs of gifted students: An analysis of intake forms at a University Based Counseling Center. Gifted Child Quarterly, 50 (1), 52-61.

Young, J. E. (1981). Cognitive therapy and loneliness. In G. Emery, S. D. Hallon \& R. C. Bedrosian (Eds.), New directions in cognitive therapy: A case book (pp.139-159). New York: Guilford. 
